\title{
Estabilidade e instabilidade sistêmica: as orações de tempo sob uma perspectiva diacrônica
}

\author{
Systemic stability and instability:
}

time clauses under a diachronic perspective

\author{
Maria Luíza Braga \\ Universidade Federal do Rio de Janeiro/CNPq \\ Maria da Conceição de Paiva \\ Universidade Federal do Rio de Janeiro/CNPq ${ }^{1}$
}

Resumo

Neste artigo, focalizamos as orações complexas de tempo sob uma perspectiva em que se conjugam as dimensões diacrônica e sincrônica. Analisamos o uso dos diferentes conectores que expressam a relação de tempo, ao longo do período compreendido entre os séculos 18 a 21, buscando identificar a estabilidade / instabilidade nas propriedades a eles associadas. $\mathrm{O}$ estudo permite mostrar a estabilidade no conjunto de conectores utilizado nesse período da história, destacando-se, sobretudo, a maior frequência de quando e enquanto. Além disso, trazemos evidências quanto à necessidade de considerar as subespecificações semânticas codificadas pelas orações temporais. As orações temporais que codificam superposição e coextensividade temporal apresentam comportamento distinto daquelas que expressam sequencialidade.

Palavras-chave

Orações de tempo, Diacronia, Propriedades semânticas, Propriedades sintáticas. 


\section{Abstract}

In this paper, we focus on temporal clauses in an approach that integrates both diachronic and synchronic dimensions. We analyze the use of different connectives which express temporal relation, during the period between the $18^{\text {th }}$ and $21^{\text {th }}$ centuries, aiming at identifying stability / instability in the proprieties related to them. First of all, this research allows us to show the stability in a set of connectives used in this period, emphasizing, especially, the high frequency of the connectives quando (when) and enquanto (while). In addition, we present evidences related to the necessity of considering semantic subspecifications codified by temporal clauses. Temporal clauses that codify superposition and temporal coextensivity display a distinct behavior from those which express temporal sequentiality.

\section{Keywords}

Time clauses, Diachrony, Semantic properties, Syntactic properties. 


\section{Introdução}

As orações adverbiais de tempo são classificadas pelas abordagens gramaticais tradicionais como estratégias de subordinação que se identificam pelos conectores que as introduzem, como se pode verificar nas citações apresentadas a seguir:

Tipos de oração subordinada adverbial - A oração subordinada adverbial funciona como adjunto adverbial da sua oração principal:

Toca sempre a sineta, quando terminam as aulas (subordinada adverbial temporal).

As orações subordinadas adverbiais iniciam-se pelo transpositor que, acompanhado de preposição ou advérbios ou de outras unidades adverbiais.

TEMPORAIS: quando a oração subordinada denota o tempo da realização do fato expresso na principal.” (BECHARA, 1999, p. 493-502)

\section{Orações adverbiais}

Assim se denominam porque, equivalentes a um advérbio, figuram como adjunto adverbialda oração a que se subordinam. Quando desenvolvidas, começam por conjunção subordinativa.

(...)

É papel da oração temporal trazer à cena um acontecimento ocorrido antes de outro, depois de outro, ao mesmo tempo que outro. Para cada um dessses aspectos possui a oração temporal, quando DESENVOLVIDA, conjunções apropriadas.” (ROCHA LIMA, 1972, p. 274-283).

As mencionadas gramáticas também se referem às sub dimensões do espaço semântico que podem ser recobertas pelas orações de tempo, concordando quanto à sinalização das noções de anterioridade, posterioridade e simultaneidade do estado de coisas da oração hipotática em relação ao estado de coisas da oração 
nuclear. A lista das subespecificações temporais é ampliada por Castilho (2010), que arrola também o tempo progressivo, e por Bechara (1999), que distingue posterioridade imediata, tempo frequentativo, tempo concomitante, tempo limite terminal.

Nos últimos anos, diversos autores têm destacado as inconsistências do tratamento oferecido pela gramática tradicional aos mecanismos de conexão oracional (MATHIESSEN; THOMPSON, 1988; LEHMANN,1988; PAIVA, 1991; DECAT, 1999; MOURA NEVES, 1997, 2001). As objeções mais incisivas dizem respeito ao reducionismo da dicotomia coordenação / subordinação e à mistura de critérios semânticos e sintáticos na classificação dos diferentes tipos de oração. Acrescente-se ainda o fato de esse tratamento se limitar, na maior parte das vezes, a uma listagem indiferenciada de conectores que podem instanciar uma relação semântica, sem atentar para as especificidades de cada um deles. Com o objetivo de recobrir lacunas dessa natureza, diversas vertentes funcionalistas têm proposto abordagens alternativas que permitem avançar, de forma, considerável, na compreensão da gradiência nos processos de combinação de orações.

É bem verdade que o tratamento das orações complexas pelos linguistas de orientação funcionalista não é homogêneo e diverge, tanto na forma como concebe a relação entre sintaxe e semântica como no que se refere ao papel dos conectores. Para diversos estudiosos, como é o caso de Halliday (2004) e Croft (2001), inexiste uma relação biunívoca entre tipo de oração e relação semântica por ela sinalizada. De acordo com o primeiro, certas relações semânticas associadas ao realce podem ser expressas por processos paratáticos, hipotáticos e de encaixamento. O segundo, por sua vez, defende que "construções "coordenadas" e "adverbiais" podem codificar aproximadamente o mesmo conjunto de relações semânticas" (CROFT, 2001 p. 328, tradução nossa).

Outra diferença concerne à dicotomia coordenação / subordinação que, embora endossada por alguns funcionalistas (cf. DIK; HENGEVELD, 1997; CRISTOFARO, 2003, por exemplo), é rejeitada por outros. Substituem-na por um continuum no qual se dispõem três processos de combinação: parataxe, hipotaxe e subordinação (Cf. HALLIDAY, 2004; MATTHIESSEN; THOMPSON, 1988; HOPPER; TRAUGOTT; 1993, 2003), ou por uma gradiência mais fina, que compreende orações independentes, orações adjungidas, díades correlativas, orações mediais, participiais, orações governadas (LEHMANN, 1988), verbos seriais, orações complemento, orações adverbiais, cadeias oracionais, orações relativas, coordenação, orações não vinculadas (PAYNE, 1997), defendem sua disposição em um espaço conceitual (CROFT, 2001) ou ainda advogam sua subs- 
tituição por uma análise dos processos de articulação sob o prisma de um conjunto de propriedades gramaticais, independentemente das noções de coordenação e subordinação (HAIMAN; THOMPSON, 1984).

O que se encontra em jogo, então, é o próprio conceito de subordinação em sua aplicação às orações complexas. Haiman e Thompson (1984), por exemplo, sustentam que, nos estudos linguisticos produzidos no ocidente, esta categoria vem sendo usada como um primitivo, sem uma caracterização precisa, ou como um processo universal. Cristofaro (2003), por outro lado, apesar de referendar a dicotomia clássica, salienta que os critérios morfossintáticos utilizados na investigação das orações complexas foram desenvolvidos com base nas línguas indoeuropeias e são de aplicação limitada tanto interlinguística quanto intralinguisticamente. Ainda segundo ela, eles podem conflitar entre si e delimitar classes de orações internamente inconsistentes.

O nosso trabalho se beneficia das investigações prévias e se restringe a um tipo particular de oração: aquelas que sinalizam a relação de tempo e que são introduzidas por um conector. As orações em pauta são examinadas sincrônica e diacronicamente com vistas a verificar sua estabilidade / instabilidade sistêmica no $\mathrm{PB}$, ao longo dos quatro últimos séculos. Por meio deste estudo, discutimos a importância de uma abordagem mais detalhada das propriedades caracterizadoras das orações complexas temporais e da polifuncionalidade dos elementos conectores e mostramos a forma como uma análise diacrônica pode contribuir para esclarecer as convergências entre diferentes tipos de oração temporal.

$\mathrm{O}$ artigo compreende três partes: na primeira, consideramos o espaço semântico recortado pelas orações de tempo; na segunda, sao investigadas as suas propriedades morfossintáticas; e a terceira expõe as considerações finais. As referências bibliográficas são apresentadas por último.

\section{O espaço semântico da relação temporal}

No registro escrito do $\mathrm{PB}$, o espaço semântico da relação temporal que se instaura entre as partes constitutivas de uma oração complexa pode ser segmentado em superposição ou simultaneidade coextensiva, ${ }^{2}$ anterioridade, anterioridade imediata, posterioridade, limite temporal e contingência. Associado a essas subespecificações, existe um conjunto de conectores que se manteve estável ao longo dos séculos $18,19,20$ e 21 , como se pode observar no quadro $1 .^{3}$ 


\section{QUADRO 1 \\ Relações temporais e conectores}

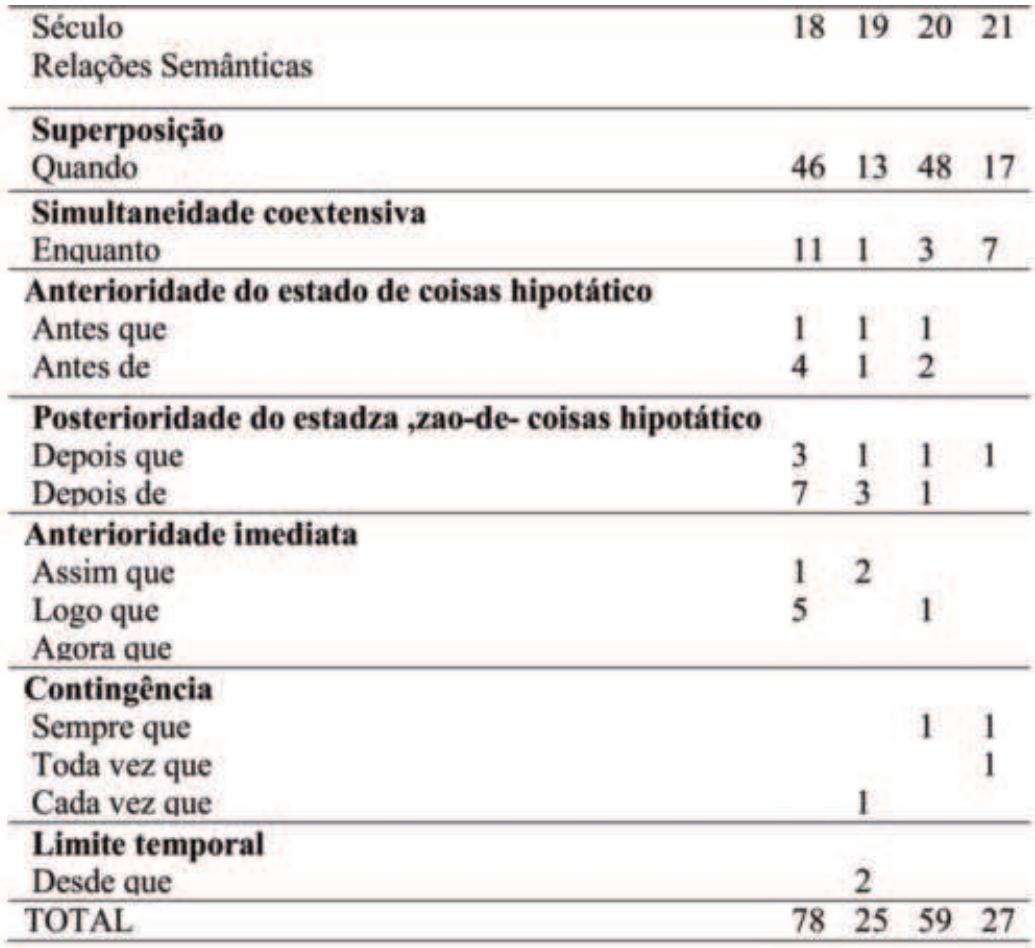

O conjunto de conectores empregados para a sinalização da relação temporal é heterogêneo no que diz respeito à sua produtividade, complexidade formal, polifuncionalidade semântica e polifuncionalidade sintática, como passamos a considerar a seguir.

Quando é o item não marcado para a expressão da relação temporal. Provém da junção do relativo quam e da preposição indo-europeia - do. (BASSOLS DE CLIMENT 1956, p. 342, apud BARRETO, 1999, p. 219). Baseando-se em Rubio (1983) e BASSOLS DE CLIMENT (1956), Barreto sustenta que quando era frequente no latim falado, embora pouco usual no latim clássico. Esta conjunção caracteriza-se por ser menos complexa formalmente, ${ }^{4}$ e mais polifuncional semântica e sintaticamente. $\mathrm{O}$ item quando integra diversas classes de palavras 
(pronome interrogativo, pronome relativo e conectivo) e, enquanto elo interoracional, presta-se à sinalização de diferentes nuances semânticas. Com efeito, quando encabeça orações às quais se pode atribuir, predominantemente, leitura de superposição, prolongada ou não (1) e de simultaneidade coextensiva (2); muitas das orações introduzidas por quando são compatíveis com duas ou mais interpretações, tais como: tempo-condição (3), tempo-causa (4), tempo-concessão (5) como se ilustra a seguir:

(...) tive notícias deCeu compadre que os Navios deparnambuco tinhão partido a 16 de maio Comque o adevinhar não esta nanossa mão e quando o navio chigou aparnambuco logo Ceu Compadre deo ordem a Carregalo para o mandar abahia para Ver se pilhava oComboyo. (Séc 18, PHPB Cartas Comerciais, p. 1, linha 9.).

Lembrando me porem, que nas circunstâncias idênticas em que se achou aCidade de Pernambuco, vio-se este immenso povo reduzido à maior extremidade de comprar por excessivo preço os generos daprimeira necessidade, que, quando outros gemiâo suprimidos da mizeria, a Providência tão liberalmene lhe concedia, e que nessa mesma occaziâo me foi indispensável refrear o dezordenado appetite de avul tados Lucros que pretendião ter os Negociantes, regulandose antespelo accrescimo dos seos Cabedaes, do que pela calamidade dos 15 Povos, eprincipalmente deste, que tinha manifesto direito áquelles generos, cuidei tão bem em reprimir maximas de commercio tão prejudiciaes. (Séc. 18, PHPB Cartas Oficias, ,p. 3, linha 8).

Ordena, que jamais se intrometâo nas diligencias de farinhas nem se encontrem com as suas disposições; Ameaça cheio deria prisão, etodos os excessos quando encontre a mais leve aoposição aas suas ordens (Séc. 18, CILP1BMRERJ Representação oficial p. 6, linha 135).

Propala-se nesta capital que sou o au- tor de uns escriptos que se publicam men-salmente na cidade de Iguape; pouco me importo com isso; não venho fazer de-clarações porque não pretendo dar satis-fações á quem quer que seja: as pessoas de brio quando se veem aggredidas em publicações recorrem á imprensa para se justificarem ou aos tribunaes para se desaffrontarem. (Séc. XIV, Cap_III,_Paraná-anapaula, Carta 217, p. 12, linha 1). 
Com osnr jose baltazar, ajuntei q. Para quinze deste mês, me avia vmce completar o que com o dito antes dapascoa, que farão $50 \$ 000$ e como estamos no ditto tempo, quizera que $\mathrm{vm}^{\mathrm{ce}}$ me mandasse aditta quantia, quando não seja tudo oq ainda esta portando, pois quem pertoda esta sema hir $\mathrm{Al}^{\mathrm{a}} \mathrm{R}^{\mathrm{a}}$. dar solução doq tenho a meu (?) e não querera $\mathrm{q}, \mathrm{vm}^{\text {ce }}$ veja a cauza deq por seu respeito receba alguma repreensão q. sertâ mente tem munta terão para mofazerem pello que tenho deicado deodobrar, para com vmce com sua resposta ficarei a sua ordem. (Séc. 18, CILP1BMCPMG- Cartas Pessoais MG, p. 1, linha 1).

As leituras listadas acimas se correlacionam a fatores de diversas naturezas, quais sejam, modo subjuntivo, no que diz respeito à expressão de condicionalidade e concessão; anterioridade do estado de coisas expresso pela oração hipotática, em se tratando de orações com acepção causal; diferença na polaridade, no caso de segmentos concessivos.

As orações introduzidas por quando se vinculam hipotaticamente a uma outra, sua nuclear. Significa isso que, de acordo com as propostas de Halliday (2004), Matthiessen e Thompson (1988), Hopper e Traugott (1993, 2003), são menos encaixadas e mais dependentes sintaticamente, a dependência sendo sinalizada pelo conector. Excepcionalmente, podem restringir um ato de fala, como se exemplifica em (6).

(6) Lembrai-vos dos idos de março de 1964, quando a velha direita colonial, apoiada na mídia, levantou a bandeira da "corrupção $e$ subversão" para derrubar o governo, dando início à longa noite das ditaduras. (Séc. 21, JB, 19-03-04, p. 1, linha 1).

A leitura predominantemente temporal resulta, em grande parte, de uma conjugação de fatores que têm a ver com o tempo / aspecto verbais, transitividade e tipo textual. No século 18, verbos de deslocamento espacial, muitos dos quais pontuais, e de processo material, com aspecto perfectivo, são predominantes. $\mathrm{O}$ rol dos tipos semânticos do predicado verbal se alarga nos séculos posteriores e passa a incorporar verbos de processo mental e verbos de fenômenos meteorológicos. É possível que a relativa especialização dos tipos semânticos dos predicados verbais esteja atrelada ao tipo-gênero textual em análise: as cartas do século 18 são administrativas, reportam as movimentações comerciais da sociedade brasileira que se efetivavam por meio de transporte marinho e daí a referência frequente 
a navios que chegam e partem. Já as cartas do século 19 são de natureza mais acadêmica e pessoal, dada a referência aos estados mentais dos emissários. Por fim, a correspondência dos séculos 20 e 21 foi extraída de jornais, alguns voltados para um público-alvo mais popular (classes $\mathrm{C}$ e D), ${ }^{5}$ e nelas prevalece a referência aos problemas provocados por fenômenos meteorológicos. Mais relevante parece ser, no entanto, o papel do aspecto e tempo verbais, importantes para a sinalização de um estado de coisas acabado e localizado deiticamente.

As orações em tela, ao introduzirem uma circunstância tempo, delineiam um quadro de referência para o que foi / está sendo / vai ser apresentado pela oração nuclear. Excepcionalmente, podem funcionar à maneira de um tópico, como se ilustra a seguir:

(7) Quando 60\% dos veículos licenciados estão em situação irregular, acho que a saída não é apertar a fiscalização, porque ninguém fabrica dinheiro para pagar suas obrigações de uma hora para outra, mas sim facilitar o pagamento, parcelando o valor das multas, reduzindo o IPVA, enfim, encontrar uma saída. É melhor receber menos de muitos, do que ficar reclamando pelos jornais. (Séc. 21, O Globo, 12-03-04, p. 4, linha 4).

Enquanto, conector que, segundo Barreto (1999) remonta ao século 13, é o segundo mais frequente. A variação na grafia, ${ }^{6}$ verificável nos séculos 18 e 19, fornece indícios quanto à sua origem: junção da preposição em à forma quanto. É possível que já no século 19 os falantes o analisassem como uma forma simples, dada a coocorrência com a preposição "em", como se pode observar em (8):

(8) (...) mas eu no emquanto nã̃ tiver ordem de Vossa excelência estou no acordo deanaõ entregar. (Séc. 18, CILP1BMCB93 corr adm pbl, 18, p. 7, linha 9).

À semelhança de quando, o item enquanto se caracteriza por polifuncionalidade sintática e semântica. Além de poder ser empregado como preposição, ${ }^{7}$ enquanto, item conjuncional, inicia orações com acepção de simultaneidade coextensiva, acepção compatível com as de condição e contra-expectativa. A última prevalece nas cartas do século 21 e é indiciada pela diferença de polaridade das orações nuclear e hipotática e / ou contraposição dos referentes dos SNs. 
(9) porque os mesmos Vice Reis depois de estes a eles se acolherem, os nam procuram mais em considerasam ao Reverendisimo Bispo, que os administra, izensam eprivilegio de que os nam deixam gozar emquanto frequentam as Aulas de Vosa Ma gestade. (Séc. 18, CILP1BMRERJ, Representao oficial XVIII, RJ 1, p. 6, linha 144).

(10) OS Juizes Ordinarios desta vila que sahiraõ nos PiLouros que eu Fis neste anno, semeopoem, para que em sendo apossador aja eu de entregar auara de Ouvidor ao Juis mais uelho, mas eu no emquanto naz̃ tiver ordem de Vossa Excelencia estou no acordo deanaõ entregar, aexemplo deAntonio Jozé Martins, que tendo amesma Jurisidisaõ sendo Juis, depois auendo nouos Juizes Ficou elle sempre con seruado no Lugar do Ouvidor ate achegada do Ouvidor destaComarca. (Séc. 18, CILP1BMCB93 corr adm pbl, XVIII, p. 7, linha 7).

(11) Um verdadeiro acinte essa greve da Polícia Federal. Enquanto outros funcionários públicos estão sem reajuste há mais de oito anos, sem perspectivas de melhoria, esses marajás pedem mais de $80 \%$ de aumento, a título de equiparação salarial. Gostaria de lembrar que os controladores de vôo (civis e militares), responsáveis por milhares de vidas diariamente, recebem no máximo $\mathrm{R} \$ 2.500$ em fim de carreira. (Séc. 21, O Globo 11-03-04, p. 3, linha 20).

Em contextos particulares, enquanto e quando são funcionalmente equivalentes, podendo ser intercambiáveis, como ilustram os trechos (2) e (9), apresentados anteriormente. $\mathrm{O}$ fato de os dois conectores serem formalmente similares e funcionalmente equivalentes em certos contextos parece constituir uma evidência a favor da hipótese segundo a qual elementos formalmente semelhantes tendem a expressar conteúdos próximos.

A anterioridade do estado de coisas da oração hipotática em relação ao estado de coisas expresso pela oração nuclear pode ser sinalizada tanto pela locução prepositiva depois de quanto pela locução conjuntiva depois que, ambas compartilhando a mesma base prepositiva depois. A menor polifuncionalidade sintática dessas locuções corresponde a uma menor polifuncionalidade semântica: depois que e depois de funcionam tão somente como conectores que servem à expressão de anterioridade temporal. 
(12) Nesta mesma noute li ao Vicerey as mencionadas cartas, fazendo dispois entrar o Juis de Fora, que repetio omesmo que me tinha referido tanto vocalmente como naparteque me deo por escrito; edepois que odito Menistro sahio, assentei com oViceRey, emque era percizo averiguar quanto fosse possivel, quem era o infame author daquella abominavel carta (Séc. 18 - CILP1PMCORJ, Carta oficial Vice-Rei, RJ, 18, p. 2, linha 19).

(13) (...) porque os mesmos Vice Reis depois de estes a eles se acolherem, os nam procuram mais em considerasam ao Reverendisimo Bispo, que os administra, izensam eprivilegio de que os nam deixam gozar emquanto frequentam as Aulas de Vosa Ma gestade. (Séc. 18, CILP1BMRERJ, Representao oficial, RJ 1, p. 6, linha 144).

As propriedades recém-mencionadas - maior complexidade formal, menor polifuncionalidade sintática e semântica - podem ser observadas igualmente a propósito do par que sinaliza a posterioridade do estado de coisas da oração hipotática ao estado de coisas expresso pela oração nuclear - antes que ${ }^{8} \mathrm{e}$ antes de, bem como a propósito das três variantes associadas à sinalização da contingência - sempre que, toda vez que e cada vez que -, ilustradas a seguir:

(14) Vay onoço amigo Filipe. Logo tomou medo aopaiz pela Rezão deque pilhou hum defluço nagaita aSim que chegou e antes que vá amais vai-çe Retirando, oque elle lhepeza he açhar quando chegar afunção deAl[eu]be feita, por que Selembrão muito bem dopaçado. (Séc. 18, PHBP Cartas Comercias, p. 6, linha 26).

(15) Quando já supunhão os Espagnoes que estavamos esmorecidos, de pertender acção alguma, eque na verdade ninguem já esperava de ter acção que fosse boa, intentou o Böhm dálla no dia acima referido; festejando primeiramente os annos da Raynha Nossa Senhora com hum magnifico banquete antes de pôr em marcha a suatropa. (Séc. 18, PHPB Cartas Pessoais, p. 3, linha 11).

(16) Sempre que nomes famosos do "comissariado" são colocados na berlinda, como ocorre agora com o escândalo da Casa Civil, aparece gente tentando abrir covas para, de seu interior, retirar salvadoras cortinas de fumaça às custas do dinheiro público. público (Séc. 21, O Globo, 11-03-04, p. 2, linha 21). 
(17) Os moradores da Avenida um, em Nova Itapeba, não suportam mais enfrentar os problemas provocados pelas chuvas. Eles ficam impedidos de sair de casa toda vez que chove porque a rua fica completamente alagada. Já foram feitas solicitações para realização de saneamento e pavimentação à prefeitura. Até quando teremos que esperar? (Séc. 19, Extra 05-01-04, p. 1, linha 13).

(18) Sempre as suas ordens | amigo. Cada vez que nos enviar uma cartinha cheia de cobres, espere por lá o que pede. (Séc. 19, Cap_III,_Paraná-anapaula,Carta 254, p. 29, linha 1).

Embora formalmente mais complexas do que quando e enquanto, os morfemas constitutivos dos últimos cinco juntores são permeáveis à inserção de itens linguísticos, como se exemplifica a seguir, o que constitui evidência de sua menor integração sintática.

(19) Antes porem de entrar em materia, me permittirá que | exprima a satisfação com que recebi sua preciosa carta. (Séc. 19, Cap_III,_Paraná-anapaula - p. 4, Carta 209, linha 9).

A locução desde que, associada à leitura de limite temporal, formada pelo produtivo processo de posposição da palavra que, neste caso, a uma base preposicional, diverge das anteriores, por ser semanticamente mais polifuncional, podendo servir à sinalização de noções temporais e causais, relações bastante imbricadas (cf. PAIVA, 1991, 1996).

(20) Sinto-me tristemente apprehensivo desde que estás eleito VicePresidente do Club Repu-blicano da Capital. (Séc. 19, Cap._3,_Paraná-anapaula, p. 37, Carta 263, linha 1).

Nas amostras em análise, são encontradas ocorrências da leitura de limite temporal (terminus ad quem, segundo KORTMAN, 1997) as quais parecem decorrer da contribuição da preposição até em anteposição a SPreps integrados por nomes associados a tempo, como exemplifica o trecho seguinte. Uma vez que o português não dispõe de um conector cuja função básica seja a sinalização desta acepção, exemplos como o apresentado serão desconsiderados. 
(21) Sempre o foi tambem ao Capitam Mor das ordenansas da mesma Villa té ao tempo, em que o Excelentissimo Senhor Marqués de Valensa, fés da Freguezia de Jequiriçá hum Terço separado de Ordenansas, em atençaõ aos Córtes das Madeiras-Reaes, que se extra- hem do dito Jequiriçá (Séc. 18, CILP1BMCB20 Corr pbl BA, p. 4, linha 4).

Uma vez consideradas as subespecificações semânticas de tempo que se associam às orações em estudo, passamos ao exame das suas propriedades morfossintáticas.

\section{Propriedades das orações hipotáticas de tempo}

Nesta seção, são apresentados, sob a forma de gráficos, os resultados para algumas variáveis de natureza morfossintática: correferencialidade entre os sujeitos das orações nuclear e hipotática, forma de expressão do sujeito, correlação modo-temporal entre orações nuclear e hipotática e posição da oração hipotática face à nuclear. Os dados correspondentes às orações introduzidas por quando e enquanto foram amalgamados, dada sua proximidade semântica e morfossintática; procedimento análogo foi adotado com respeito às orações associadas à sequencialidade. Os resultados referentes às demais orações foram desconsiderados face ao número diminuto de ocorrências, o que inviabilizava generalizações confiáveis. 


\section{GRÁFICO 1}

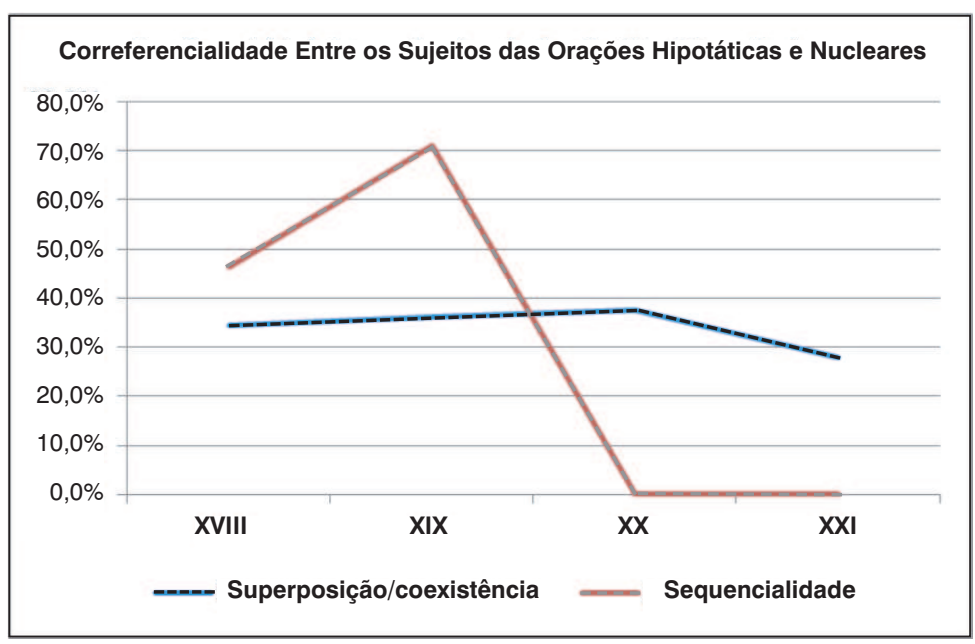

As orações temporais associadas a superposição / coexistência, por um lado, e à sequencialidade, por outro lado, apresentam distribuição divergente, no que concerne à correferencialidade entre os sujeitos das orações hipotática e nuclear. Enquanto as primeiras se caracterizam por uma relativa estabilidade ao longo dos séculos considerados, as segundas exibem um pico de correferencialidade no século 19, e não são mais encontradas, no gênero textual em exame, nos séculos 20 e 21.

No que diz respeito à variável forma de expressão do sujeito das orações hipotáticas, as orações que exprimem uperposição/coexistência, por um lado, e aquelas que expressam sequencialidade, por outro lado, exibem, novamente, uma distribuição diferente, embora convergente nos dados correspondentes ao século 21 , isto é, caracterizam-se por preenchimento categórico (orações que exprimem sequencialidade) ou quase categórico (orações que expressam superposição / coexistência). A diferença entre elas concerne à distribuição ao longo dos outros três séculos: enquanto as orações sequenciais apresentam um aumento gradual e persistente de preenchimento, as outras mostram um decréscimo da realização do sujeito por meio de SNs plenos. Essa redução também é gradativa e atinge seu ápice no seculo 19. 


\section{GRÁFICO 2}

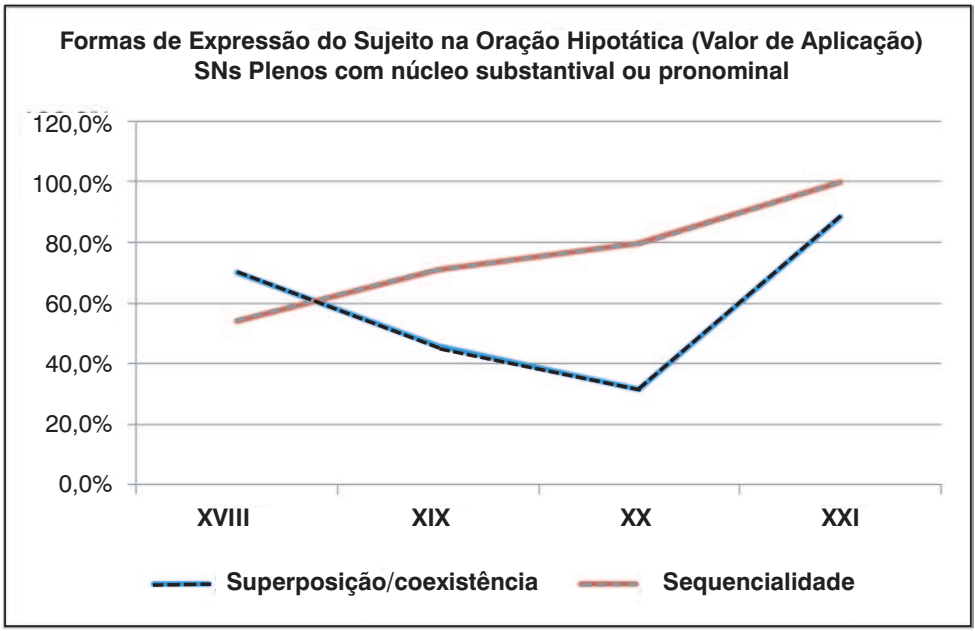

\section{GRÁFICO 3}

Formas de Expressão do Sujeito na Oração Nuclear (Valor de Aplicação) SNs Plenos com núcleo substantival ou pronominal

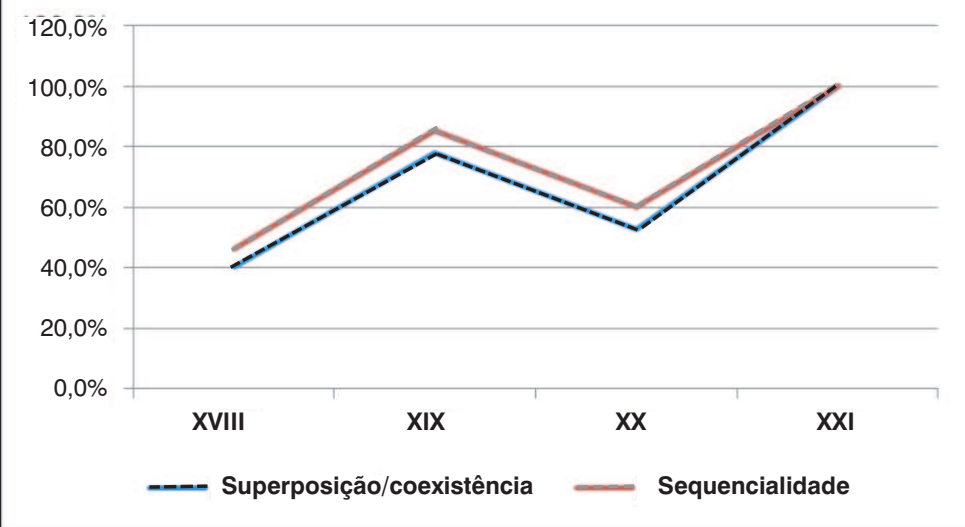




\section{GRÁFICO 4}

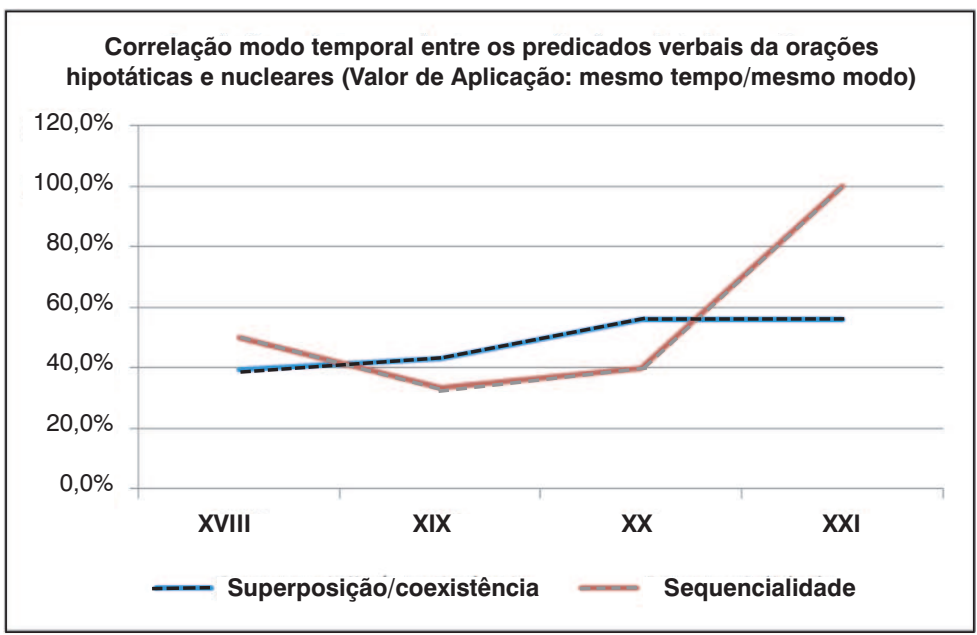

Os resultados para a variável Forma de expressão do sujeito da oração nuclear são paralelos para os dois tipos de orações e sugestivos de instabilidade sistêmica. Conformam-se às tendências mais gerais do PB que se caracteriza pelo maior preenchimento do sujeito nas últimas décadas. (cf., por exemplo, DUARTE, 1995, 2003).

O grupo de fatores Correlação modo-temporal entre os predicados verbais das orações hipotática e nuclear revela a maior estabilidade das orações associadas a superposição / coexistência. As orações que exprimem sequencialidade, por seu turno, estáveis até o século 20, apresentam uma elevação dos índices para identidade modo-temporal das formas verbais, no século 21 .

A seguir, são discutidos os resultados para a variável Posição da oração hipotática face à oração nuclear. 


\section{GRÁFICO 5}

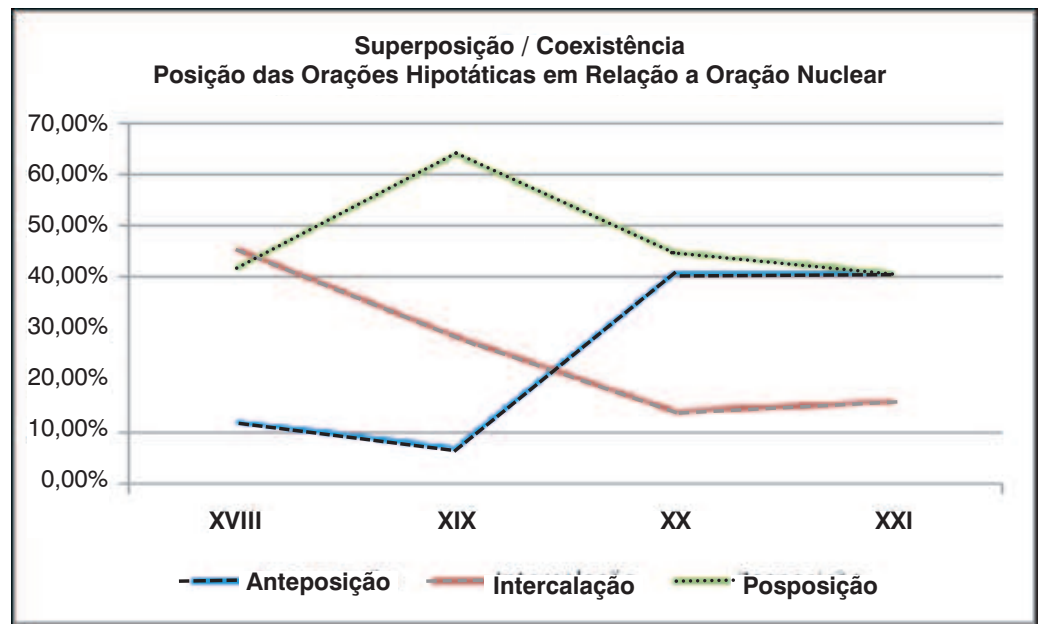

\section{GRÁFICO 6}

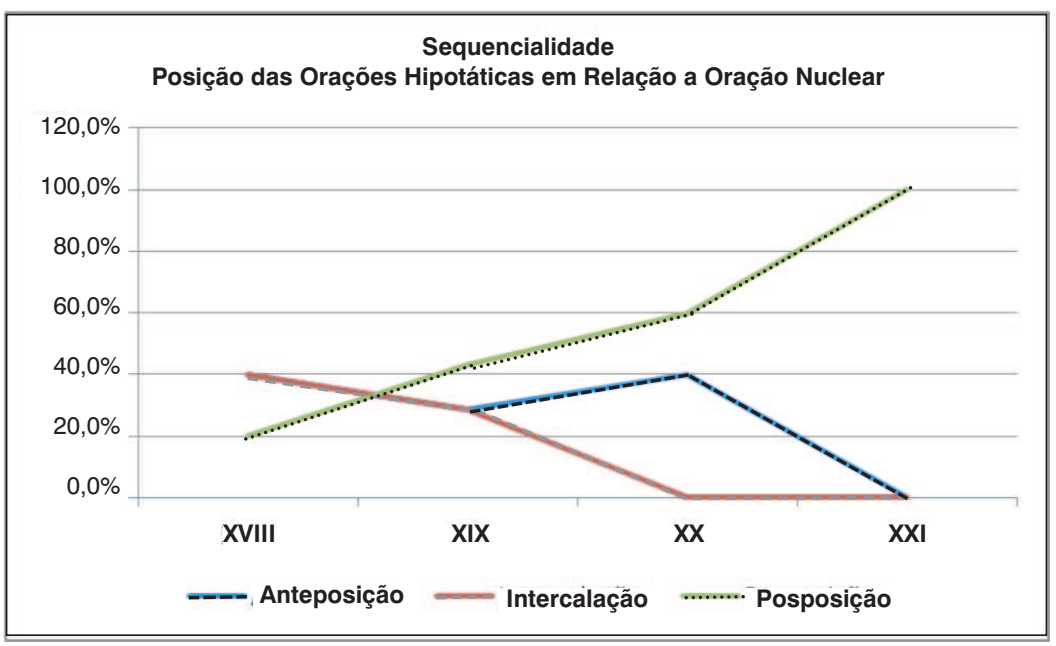


O GRAF. 5 desvela sutis e persistentes alterações no que diz respeito à posição das orações que exprimem superposição/coexistência entre dois estados de coisas relacionados. Observa-se a contração gradual e contínua de empregos de orações intercaladas no intervalo entre os séculos 18 a 20, verificando-se uma certa estabilização no período compreendido pelos dois últimos séculos. Estabilização semelhante, no mesmo período, pode ser igualmente percebida a propósito da anteposição e posposição, embora às custas de distribuições prévias diferentes, vale dizer, retração de posposição e amplificação de anteposição. A distribuição quase idêntica para posposição e anteposição, nos séculos 20 e 21, dificulta a identificação de uma ordem não-marcada no genero epistolar produzido pela mídia carioca e sugere que, quanto a este fator, as diferenças entre escrita e fala estão tendendo a se neutralizar.

Com respeito às orações associadas a sequencialidade, nota-se igual rarefação de orações intercaladas, distribuição que se contrapõe às obtidas pelas orações pospostas e antepostas. Com efeito, no GRAF. 6, vê-se que os empregos de orações antepostas tendem a diminuir enquanto os de pospostas, a ampliar.

As motivações que levam à opção pela anteposição ou posposição relacionam-se a fatores discursivos e são próximas àquelas observadas para a fala. Com efeito, ao examinar as orações complexas de tempo nessa modalidade, Braga (2003) verificou uma hipótese proposta por Thompson (1985), e retomada por Ford (1988), segundo a qual, no inglês, as diferentes posições das orações de tempo em relação à oração núclear decorriam do seu papel textual. Orações temporais antepostas às nucleares tendiam a criar o pano de fundo, a orientação temporal para os eventos que seriam referidos posteriormente, daí, poderem incidir sobre mais de uma oração. Temporais pospostas, por sua vez, delimitavam, restringiam a asserção codificada pela oração nuclear. No português falado, a correlação se sustentou e o mesmo efeito ocorre com os dados diacrônicos em exame. Desnecessário recordar que a correlação é variável e que sua aplicação a dados diacrônicos é mais delicada, dada a maior liberdade de pontuação gráfica observada na correspondência dos séculos anteriores.

(22)Quando fui para hesasidade beiar os pes de vossa excelenca naõ tive lugar dedar contas pelamuita ocopasam emque vossa excelenca seachava naocaziam (.) aigreia da aldea denosasenhora daescada, aqual tenho reetificado aminha custa por servir anosasenhora easuamagestade que deos guarde para que asim seaumentaseasua aldea que estava iaqua e para cair noxam por ser feita deparede 
deman em algû tempo. (Séc. 18, CILP1BMCASP 2, Carta Aldeamento de índios, SP 1, p. 1, linha 1).

(23) Rogo-lhe o favor de ver se dispoe logo do | fumo, antes que baixe muito (Séc. 18, CILP1BMCASP 2 Carta, Aldeamento de índios, SP 1, p. 1, linha 1).

O que esta seção mostra, então, é que a variabilidade morfossintática das orações de tempo é sensível ao tipo de conector que introduz a oração hipotática, justificando-se, dessa forma, um tratamento a partir das subespecificações semânticas associadas à oração.

\section{Considerações finais}

$\mathrm{Na}$ análise desenvolvida nas seções anteriores, procuramos mostrar que uma abordagem mais detalhada das orações temporais requer considerar, por um lado, as especificidades semânticas introduzidas por diferentes conectores e, por outro, as propriedades tanto da oração núcleo como da oração temporal. Uma primeira constatação que se destaca é que a forma diferenciada como cada conector recorta o continuum temporal culmina numa certa associação com algumas propriedades morfossintáticas que se mantém mais ou menos estável ao longo do tempo.

Ao considerar a distribuição dos conectores temporais em diferentes períodos do português, foi possível depreender especificidades no percurso de conectores que instanciam simultaneidade / superposição entre dois estados de coisas e dos que expressam sequencialidade. As primeiras se caracterizam por maior regularidade na tendência a sujeitos [- correferencial]; as segundas, por sua vez, oscilam de forma mais evidente entre sujeitos [+ correferencial] e [- correferencial] e mantêm esta particularidade no estágio atual do português.

Um segundo aspecto a ressaltar diz respeito às propriedades mais gerais dos períodos complexos temporais, independentes das particularidades de cada conector e, consequentemente, da forma como é recortado o espaço temporal. No que se refere, por exemplo, à flexibilidade de posição, a análise permitiu mostrar o decréscimo regular de temporais intercaladas em proveito das posições periféricas (antepostas ou pospostas). Vimos ainda que, no geral, essas duas possibilidades de ordenação mantêm menor estabilidade, consti- 
tuindo um parâmetro mais susceptível de alterações ao longo do período considerado.

No entanto, impõe-se cautela na interpretação das tendências verificadas em razão dos problemas metodológicos, nem sempre transponíveis, decorrentes das dificuldades e limitações inerentes ao estudo diacrônico. A opção por concentrar a análise em um gênero específico, no caso o macrogênero cartas, embora tenha o mérito de neutralizar o possível efeito de algumas variáveis, não resolve todos os problemas. A observada produtividade ou raridade de alguns conectores temporais, e mesmo de algumas formas de especificação temporal, ao longo do tempo, pode ser uma decorrência do fato de que, neste macrogênero, estão incluídos textos com objetivos comunicativos distintos, como é o caso das cartas administrativas e das cartas de leitores. O enviesamento na distribuição desses tipos de cartas por período, cartas administrativas nos séculos 18 e 19 e cartas de leitores nos séculos 20 e 21 - impede afirmações mais seguras acerca da inexistência ou redução de uma determinada possibilidade estrutural naquele momento.

\section{Notas}

${ }^{1}$ Este trabalho contou com a colaboração dos bolsistas de IC Rogério dos Santos Júnior e Vinicius Oliveira de Lima.

${ }^{2}$ Superposição, por um lado, e simultaneidade coextensiva, por outro, distinguem-se, na medida que a primeira exprime um espaço de tempo mais claramente recortado e que não é compartilhado em sua inteireza pelo estado de coisas expresso pela outra oração nuclear. No caso de simultaneidade coextensiva, o espaço temporal expresso pelas duas orações é compartilhado, se não na sua inteireza, pelo menos na sua maior parte.

${ }^{3}$ A amostra utilizada neste estudo é composta de cartas administrativas, para os séculos 18 e 19 e de cartas de leitores, para os séculos 19 e 20. As cartas administrativas integram o corpus de textos diacrônicos, organizado por Torrent (2009). As cartas de leitores foram extraídas de jornais de grande circulação na cidade do Rio de Janeiro e constituem parte da Amostra do Discurso midiático, organizada pelos membros do Projeto Peul.

${ }^{4}$ De acordo com Kortmann (1997, p. 78), os subordinadores adverbiais podem ser distribuídos quanto à complexidade formal, em seis classes: morfema único monossilábico, morfema único polissilábico, mais que um morfema, embora ainda uma única palavra, 
mais que uma palavra, subordinadores adverbiais discontínuos, subordinadores adverbiais que constituem padrões (por exemplo: a série wh-ever, em inglês).

${ }^{5}$ Neste grupo se incluem os jornais Extra e Povo.

${ }^{6}$ Foram encontradas as seguintes grafias: eem quanto, emquanto, no emquanto, em quanto, enquanto.

${ }^{7}$ Quando cheguei à Suíça, enquanto psicóloga portuguesa, muitos psicólogos, psiquiatras e professores me perguntavam (..) < www.cigabrasil /ch/informandooo/materiais/Psicologia_Marta $2 . \mathrm{html}>$

${ }^{8}$ De acordo com Barreto (1999), a construção antes que já é atestada no século 16 e remete a ante forma que, em latim, podia ser categorizada como preposição e advérbio e usada com sentido temporal e espacial. A acepção temporal pode ser observada no exemplo seguinte: E vos dixe, antes que me partisse, o que me parecia do negocio da Inquisiçã (CT. CLXV, 1. 01-2, apud BARRETO, 1999, p. 33).

\section{Referências}

BARRETO, T. Gramaticalização das conjunções na história do português. 1999. Tese (Doutorado em Letras), Instituto de Letras, Universidade Federal da Bahia, Salvador. BECHARA, E. Moderna Gramática Portuguesa. $37^{\mathrm{a}}$ ed. Rio de Janeiro: Lucerna, 1999.

BRAGA, Maria Luiza. Os eunciados de tempo no português falado no Brasil. In: MOURA NEVES, M. H. (Org.) Gramática do Português falado, v. VII: Novos Estudos. Campinas, Editora da UNICAMP, 2003, p. 445-459.

CASTILHO, A. T. Nova gramática do Português Brasileiro. São Paulo: Contexto, 2010.

BASSOLS DE CLIMENT, M. Syntaxis latina. V. 1 / 2. Madri: Barnejo, 1956. CRISTOFARO, Sonia. Subordination. Oxford: Oxford University Press, 2003.

CROFT, William. Radical Construction Grammar: Syntactic Theory in Typological Perspective. Oxford: Oxford University Press, 2001.

DECAT, M. B. N. Uma abordagem funcionalista da hipotaxe adverbial em português. Revista Série Encontros (Descrição do Português: abordagens funcionalistas), ano XVI, n.1, Araraquara, SP: UNESP, p. 299-318,1999.

DIK, S; HENGEVELD, K. The theory of functional grammar. Berlim / New York: Mouton de Gruyter, 1997.

DUARTE, M. E. L. A perda do princípio "evite pronome no português brasileiro". (1995) Tese (Doutorado em Linguística) - Instituto de Estudos da Linguagem - IEL Universidade Estadual de Campinas, 1995.

DUARTE, M. E. L. A evolução na representação do sujeito pronominl em dois tempos. 
In: PAIVA, M. C. A. de; DUARTE, M. E. Mudança linguística em tempo real. Rio de Janeiro: Contra Capa/Faperj, 2003, p. 115-128.

FORD, Cecilia. Grammar in ordinary interaction: the pragmatics of adverbial clauses in conversational English. Ph.D. Dissertation - University of California - UCLA, 1988.

HAIMAN, J; THOMPSON, S. Subordination in universal grammar. BERKELEY LINGUISTIC SOCIETY, 10. Proceedings... Berkeley, CA, 1984, p. 510-23.

HALLIDAY, M. A. K. An introduction to functional grammar. London: Edward Arnold, 2004.

HOPPER, P.; TRAUGOTT, E. Grammaticalization. Cambridge: Cambridge University Press, 1993.

HOPPER, P; TRAUGOTT, E. C. Grammaticalization. 3. ed. Rev. e ampl. Cambridge: Cambridge University Press, 2003.

KORTMAN, B. Adverbial subordination: a typoloqy and history of subordinators based on European languages. Berlim / New York: Mouton de Gruyter, 1997.

LEHMANN, Christian. Towards a Typology of Clause Linkage. In: THOMPSON, S; HAIMAN, J. (Org.). Clause Combining in Grammar and Discourse. Amsterdam / Philadelphia: John Benjamins, 1988. p. 181-225.

MATTHIESSEN, C.; THOMPSON, S. The structure of discourse and 'subordination. In HAIMAN, J.; THOMPSON, S. (Ed.) Clause combining in grammar and discourse. Amsterdam / Philadelphia: John Benjamins Publishing Company, 1988, p. 275-329.

MOURA NEVES, M.H. A articulação de orações: reflexões de base funcionalista. In: CONGRESSO NACIONAL DA ABRALIN, 1, 1997. Maceió. Anais.... Maceió, Universidade Federal de Alagoas, 1997. p. 271-281.

MOURA NEVES, M. H. O tratamento da articulação de orações. In: NEVES, M.H.M. (Org.) Descriçao do português: definindo rumos de pesquisa. Araraquara: FCL/Laboratório Editorial/UNESP, São Paulo: Cultura Acadêmica Editora, 2001. p. 51-66.

PAYNE, Thomas E. Describing morphosyntax: a guide for field linguistics. CUP: Cambridge, 1997.

PAIVA, M. C. de. Ordenação de cláusulas causais: forma e função. 1991. Tese (Doutorado em Linguística) - Faculdade de Letras, Universiade Federal do Rio de Janeiro - UFRJ, Rio de Janeiro, 1991.

PAIVA, M. C de. Pressupostos semânticos e pragmáticos da relação de causalidade. In: MACEDO, A. T.; RONCARATI, C.; MOLLICA, M. C. (Org.) Variação e discurso. Rio de Janeiro: Tempo Brasileiro, 1996. p. 63-74.

ROCHA LIMA, E. Gramática normativa da língua portuguesa. Rio de Janeiro: Editora José Olímpio, 1972.

RUBIO, L. Intróduccion a la sintaxis estructurale del latim. Barcelona: Ariel, 1983. THOMPSON, S. Grammar and written discourse: initial and final purpose clauses in English. Text, n. 5, p. 55-84, 1985. 
TORRENT, T. T. A Rede de Construções em Para (SN) Infinitivo: uma abordagem centrada no uso para as relações de herança e mudança construcionais. 2009. $166 \mathrm{fl}$. Tese (Doutorado em Linguística) - Faculdade de Letras, Universidade Federal do Rio de Janeiro, Rio de Janeiro, 2009. 
